\title{
Assessing Community Health Workers Compliance to who Best Practices for Safe Injection of Contraceptive in a Rural Community Setting of Tanzania
}

\author{
Article by A. Kalolella ${ }^{1}$, D. Danda ${ }^{2}$, I. Nyarusi ${ }^{3}$, J. Baraka $^{4}$, A. Rusibamayila ${ }^{5}$, E.

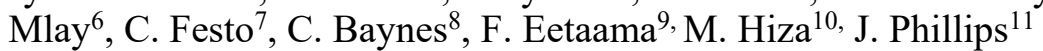 \\ 1, 2, 4, 6, 7 Ifakara Health Institute, Dar es Salaam, Tanzania, \\ ${ }^{3,10}$ Ministry of health and Social Welfare, \\ ${ }^{9}$ Dar es salaam, Tanzania \\ 5, 8, 11 Columbia University, New York, United States \\ ${ }^{1}$ E-mail: kalolella@hotmail.com
}

\begin{abstract}
The objective of this study was to assess Community health workers (CHW) compliance to WHO guideline of safe injection steps in community settings. The cross sectional descriptive study design using structured observation checklist was adopted to collect injection safety steps data. The CHWs trained to provide injectable contraceptive were direct observed by reproductive health nurse while administering intramuscular injection to women in need of injectable contraceptiveas part of family planning program in Kilombero district, Tanzania. About 1704 women received injection from 35 trained CHW. In this study we assessed if intramuscular injection and infection prevention steps taken complied to WHO based best practices for safe injections when CHW interacted with client.

Results: Majority of CHW complied to WHO best practice for safe injection: Over $89 \%$ steps for infection prevention measures and over 91\% steps for intramuscular injection technical performance complied to WHO safe injection guideline. The result also shows that CHW are likely to comply to WHO safety when they conduct injection at their own homes compared to other locations; infection prevention at CHW's home $-90.7 \%$, health centre $80 \%$, client home $-77 \%$ and $59.4 \%$ in other settings, while intramuscular injection steps; CHW's home $-89.6 \%$, health centre- $83.1 \%$, patient's home $-84 \%$ and other places $-81 \%$. Young CHW aged 18-25 years are highly likely to comply to the guideline for infection prevention steps by $79.3 \%$ compared to $77.2 \%$ CHWs aged 25 years and above, while for safe intramuscular steps $-91.7 \%$ for CHW aged 17-24, and 82.4\% for CHW aged over 25 years.
\end{abstract}

Keywords: WHO Compliance, Safe injection procedures, community health workers, Blood borne infection, intramuscular injection technical performance, infection prevention.

\section{Introduction}

Noncompliance to World health organization (WHO) injection guideline leads to unsafe injection and poor waste management that leads to increasing direct health care cost and causing millions of deaths. Non compliance causes various diseases acquired from contaminated injection, inappropriate injection technical performance and poor handling of biological waste from injection procedures (Nilsson et al., 2013, WHO, 2010). Non compliance to WHO injection guideline is public health issue that need to be dressed in order to prevent transmission of blood born infections during this era of increasing use of informal health care workers, particularly community health workers (CHW) to provide injectable medication (Nilsson et al., 2013, WHO, 2010; Olawo et al., 2013; Brunie et al., 2011 ). Implementing safe injection procedure is one of the major challenges that developing countries health care service providers are facing (Gyawali et al., 2013). Unsafe injection is the one that lead to transmission of different types of pathogens, including bacteria, parasites, viruses, bacteria and fungi and also cause non-infectious adverse events such as abscesses and toxic reactions. (WHO, 2010; Pruss et al., 2005). 
Texila International Journal of Public Health

Volume 5, Issue 1, Mar 2017

In 2010, in sub-saharan Africa alone, non compliance to injection guidelines contributed to 1.9 million cases of HIV infection, which is $17 \%$ of new HIV infection due to unsafe injection procedures (Nilsson et al., 2013). Health care workers (HCW) in sub-Saharan Africa are more exposed to waste that are highly infectious including contaminated needles, sharps, and syringes that causing them annual estimated infection of 16,000 of $\mathrm{HCV}$ infections, 66,000 HBV and 1,000 HIV infections (Pruss-Ustun et al., 2005; WHO, 2010; Nilsson et al., 2013). In Many African nations waste is burn in open places exposing surrounding people with hazardous substances (Nilsson et al., 2013). The recommended solution to address the problem of non compliance is to involve all necessary stakeholders in the training and appropriate educational program. Effective management policy and active participation of stakeholders responsible for injection activities can help reduce unsafe injection practice effectively (Gyawali et al., 2013). All governments, health professionals, patients and communities in general are responsible to ensure safety for injection procedures (WHO, 2010).

WHO recommends safe injection procedures in its guideline manual as the best practice for safe injection. Unfortunately almost half of the developing nations do not follow WHO guideline for safe injection procedures (Nilsson et al, 2013; WHO, 2010). The guideline indicates how to conduct safe injection, how to dispose syringes, sharps and other health care waste (WHO, 2010). Best injection practice as dictated in the injection guideline by WHO is the one that is performed aiming at protecting patients, health workers and the community from contaminated post-injection waste (WHO, 2010). WHO Best infection control practices for injections advocate for use of new sterile single-use injection equipment for each procedure, while HCWs are required to discard any injection package that is damaged (WHO, 2008, WHO, 2010, WHO, 2015). Providers are required to anticipate and take measures to prevent needle stick by preparing and preventing sudden patient movement and avoiding recapping and other manipulation of needle or if necessary use a single-handed scoop recapping technique (WHO, 2015). Providers are required to collect used injection equipment at the point of use in a sharps container that has no leakages and is puncture proof that can be sealed-shut during transportation to disposal site (WHO, 2015). The guideline for safe injection put emphasis on separation of infectious waste from non-infectious waste, sharp from non- sharp and be disposed at different containers while avoiding overfill of the waste collecting container to reduce risk of exposure to needle stick injury (NSI) and infections (Pruss et al., 2005;Nilsson et al., 2013; WHO, 2010). Disposal of waste should be done in the standard incinerator that complete destroy and disinfect all infectious materials that can be buried or disposed elsewhere. The HCWs are at risk of post-injection NSI due to fault of injection technical performance. The NSI is estimated to cause $23-62 \%$ of new HBV and $7 \%$ for HCV. In 2003, WHO published the NSIs in HCWs showing that there were 3 million accidental episodes of needle-stick injuries which caused 37\% of all new HBV incidences in HCWs, 39\% of new HCV cases and about $5.5 \%$ of new HIV infections (WHO, 2015). An accidental needle-stick injury (NSIs) is common observed to health care workers who have poor knowledge of handling sharps before and after use including infected ones before disposal, while recapping needle after it has been used is among high risk practices (NILSSON et al., WHO, 2015; Hunter, 2007). The contamination of CHW's hands and working environment surface may also transmit blood borne pathogens among HCW and patients (Pruss et al., 2005, WHO, 2010). Compliance to safe injection procedure is the only solution to reduce harm and limit exposure to blood borne disease for both, patient receiving injection and the services provider (WHO, 2015).

The use of CHW to provide primary health care is now growing, changing their role from health promotion and disease prevention to provision of curative services using injectable medication (Parez et al., 2009; Kate et al., 2013; Coffey et al., 2012; Brunie et al., 2011). There is an increase of African countries to use community health workers (CHW) to provide health care services in hard to reach and rural areas (Parez et al., 2009; Olawo et al., 2013; Kate et al., 2013). Critical shortage of clinical staffs is the main cause that pushed many 
African countries to use CHW to administer health care services to increase access of preventive and curative care (Parez et al., 2009; Olawo et al., 2013; Burke et al., 2014). This changing perspective of using CHW has been observed to be successful in Sub-Saharan Africa including Kenya, Madagascar and Uganda, countries with critical shortage of health care staffs. In these countries CHW have been used to provide mainly injectable family planning services. Studies indicate the CHW has been used successfully to prevent neonatal sepsis through provision of pre-dosed gentamycin in Nepal (Coffey et al., 2011).

Tanzania has started using CHW to administer injectable medication as community based services to increase access of injectable contraceptive since 2015. This is one of national efforts to ensure availability and accessibility of injectable contraceptive to reduce unmet needs of family planning.

Tanzania is one of many African countries that have high prevalence of HIV infection (Nilsson et al., 2013. Recently study conducted in Tanzania indicates that health care workers have inadequate knowledge of risks associated with unsafe injection practice and postinjection waste (Nilsson et al., 2013). The study also indicated that $46 \%$ of health care workers had NSI for the past five years, while 50\% were exposed to blood in their mucus membrane or skin wounds (Nilsson et al., 2013). Despite all injection activities conducted by the community health workers in the country, few information is available on CHW compliance to WHO guideline on safety, waste disposal and technical perceptive of intramuscular injection. While few data on unsafe injection is available, unsafe injection will continue to transmit blood bone diseases in Tanzania. If this situation is not brought to the control unsafe injection practices will continue to fuel blood borne diseases such as Ebola, malaria, Marburg viruses and hemorrhagic fevers in Africa (WHO, 2015).

We planned to evaluate the compliance to WHO injection guideline of a paid community health worker employed by a non- government organization that was trained and supervised by Ministry of health. This Study has assessed the safety infection prevention and technical performance procedures as WHO guidelines elements for safe injection during CHW's performance of intramuscular injection in the community setting at Kilombero district in southern Tanzania.

\section{Methodology}

About 35 CHWs with ordinary level secondary education were trained for one month to administer injectable contraceptive. The trained CHWs were later deployed to the community to administer intramuscular injection of medroxyprogesterone acetate as part of family planning program in Kilombero district, southern part of Tanzania.

The cross sectional descriptive study design was used to collect data. The structured direct observation checklist form was used to collect information of injection processes and safety steps. The checklist was prepared using guidelines of the Tanzanian Ministry of Health adopted from WHO guidelines for safe injection (Nilsson et al., 2013; WHO, 2010, Tanzania, 2004). About 12 registered reproductive health nurses participated to conduct direct observation of injection steps being performed and filled direct observational checklist form. Nurses direct observed and filled the direct observation form for CHWs who were administering injection for at least 24 injections for each CHW for the period of June-2015 to May 2015. The close-ended checklist of injection performance steps were defined as 0 for non- compliance and 1 as compliance to safe step of intramuscular injection respectively. The first part of checklist form was the demographic characteristic including age and sex of CHW performing the injection steps. The second section was infection prevention steps conducted by CHW while using syringes, needles, sharps, pads and other blood contaminated materials and third one is recommended safe steps of injecting the DMPA. The injection observation was conducted at setting convenient for client either at client's home or at CHW's home, nearest health facility or other places. 
Texila International Journal of Public Health

Volume 5, Issue 1, Mar 2017

\section{Ethical consideration}

The study was approved by the Medical Research Coordinating Committee of National Institute for Medical Research (NIMR) while research clearance was obtained from Ifakara health Institute and I formed consent was sought from women receiving injection.

\section{Data analysis}

EpiData software was used to develop data entry screen for processing of direct observation checklist. Data analysis was performed using Stata version 13 (College Station, Texas). Variables were categorized as: Age and sex of CHW, settings of giving injection, Infection prevention and intramuscular injection technical performance compliance procedures. Frequencies tables and cross tabulations were used to determine compliances to WHO recommended safe intramuscular steps and associations between variables. The infection prevention steps observed were; (1) washing hands well with soap and water or apply alcohol hand rub on the hands, (2) drying hands with a clean single use towel or let them air dry, (3) Opens (appropriate size) sterile package for syringe/needle, (4) Do not recap needle to avoid needle stick injury, (5) Cleans injection site with dry swab (without using any antiseptic), (6) washing hands with soap and water or apply alcohol hand rub on both hand after the procedures (7), Do not massage injection site, (8) Instructs the client not to massage after injection to avoid introducing infection to injection site, and (9) discards the used syringe and needle into the safety-box (WHO, 2015, Hunter, 2007). Intramuscular injection technical performance compliance steps observed are: (1) checks the vial for content, dose, and expiration date, (2) mix the contents by rolling bottle between palms or shakes gently to homogenize the solution, (3) correctly filling of syringe with contents of the bottle, (4) expels air from syringe without pushing any of the DMPA out, (5) Inserts needle deep into the deltoid muscle, (6) aspirates to ensure needle is not in a vein, (7) inject the entire contents of the syringe. (WHO, 2015, Hunter, 2007).

For categorical data, the proportional and confidence interval are presented with nonoverlapping confidence suggesting a significant difference. Data were analyzed into two ways. (1) Overall compliance of CHW to WHO steps of safe injection in the areas of: (a) infection prevention steps and (b) intramuscular injecting steps. (2) Cross tabulations to determine if age, sex and setting or places of giving injection were associated with compliance to WHO safe injection in the above mentioned areas of infection prevention steps and intramuscular injecting steps. In cross tabulation, performance of these steps were quantified and categorized as very well if $\mathrm{CHW}$ provided injection to client with all steps complied to WHO safe practise (100\% compliance), well for $75-99 \%$ and Fair for $50-74 \%$ and poor if less than $50 \%$.

\section{Results}

A total of $35 \mathrm{CHW}$ were assessed for injection safety steps compliance. Among CHW participated, 8 were aged between 15-24, and 27 aged between 25- 45, while 21 of them were male and 14 were female (Table 1). There were a total of 1717 DMPA injections administered by CHWs of which all steps were direct observed by Nurses and checklist forms filled: Among the filled forms 13 were excluded due to incomplete information. The total of 1704 forms was included for data analysis.

\section{Overall compliance of CHW to WHO infection prevention steps}

In infection prevention steps, majority of injections administered by CHWs complied to WHO practice for safe infection prevention steps (Table 2).

The overall percentage of compliance to WHO Infection prevention for each step are indicated below (Table 2, Overall column):

1. washing hands well with soap and water or apply alcohol hand rub on the hands, $96.7 \%$

2. drying hands with a clean single use towel or let them air dry, $93 \%$

3. Opens (appropriate size) sterile package for syringe/needle, $93 \%$ 
4. Cleans injection site with dry swab (without using any antiseptic), $95.6 \%$

5. Do not massage injection site, $94.7 \%$

6. Instructs the client not to massage after injection to avoid introducing infection to injection site, $89.1 \%$

7. Do not recap needle to avoid needle stick injury, $96.2 \%$

8. Discards the used syringe and needle into the safety-box $96.2 \%$ and

9. Washing hands with soap and water or apply alcohol hand rub on both hand after the procedures, $89.7 \%$.

\section{Overall compliance of CHW to WHO safe intramuscular DMPA injecting steps}

Majority of injections administered by CHWs complied to WHO practice of safe DMPA intramuscular injecting steps (Table 3, Overall column). The overall percentage of compliance to WHO intramuscular injecting steps for each step are indicated below (Table 3).

1. Checks the vial for content, dose, and expiration date, $92.9 \%$

2. Mix the contents by rolling bottle between palms or shakes gently to homogenize the solution, $94.1 \%$

3. Correctly filling of syringe with contents of the bottle, $95.8 \%$

4. Expels air from syringe without pushing any of the DMPA out, $91.6 \%$

5. Inserts needle deep into the deltoid muscle, $95.9 \%$

6. Aspirates to ensure needle is not in a vein, $96.2 \%$

7. Inject the entire contents of the syringe, $96.4 \%$.

Cross tabulations to determine if age, sex and setting or places of giving injection were associated with compliance to WHO infection prevention steps

In infection prevention steps, cross tabulation, performances of these steps were quantified and categorized (Table 4). The result indicates that when compliance was quantified, about $79 \%$ of injection performed by $\mathrm{CHW}$ aged between $18-25$ years and $77 \%$ of injection administered by CHW aged $25-45$ years were done very well $(100 \%$ compliances with all step collect complied to WHO guideline) (Table 4). Although the compliance of CHW aged $17-24$ looks higher than $25-45$ years age, but since the confidence intervals overlap each other, then the difference is not significant. The CHW aged 17-24 had no (0\%) none compliance to WHO safe steps of injection administration compared to aged 25-45 who had $3.9 \%$ non compliance to WHO safe injection (Table 4). The highest compliance of infection prevention (Very well) was $94.9 \%$ for male compared to $80.5 \%$ for female. There is an indication that male performance was better than that of females but the difference was not statistically significant. The none compliance was more for female $4.2 \%$ compared to male $1.8 \%$. The result also shows the different in compliance to infection prevention step is significance if injection was conducted at CHW's home than another location. The infection prevention steps compliance based on setting where injection was administered: CHW's home by $90.7 \%$, health centre by $80 \%$, client home by $77 \%$ and $59.4 \%$ in other settings (Table 4). Poor infection prevention performance was more observed at other places by $4.5 \%$ followed by client home of $3.7 \%$ and $0.3 \%$ at CHW's home. No non compliance $(0-50 \%)$ was observed at Health centre setting (Table 4).

Cross tabulations to determine if age, sex and setting or places of giving injection were associated with compliance to WHO intramuscular injecting steps

In intramuscular injecting, the result indicate that $91 \%$ of injections performed by CHW aged 17-24 were very wells (100\% complied), while CHW aged between $25-45$ administered $82 \%$ of intramuscular injection with all steps complied (Table 5).

The CHW aged 17-24 had no none compliance performance while aged 25-45 had none compliance of $4 \%$ and the difference is statistically significant since the confidence interval doesn't overlap (Table 5). The Compliance to intramuscular injecting steps indicate compliance of $91.7 \%$ among $\mathrm{CHW}$ aged $17-24$, and $82.4 \%$ of $\mathrm{CHW}$ aged between $25-45$, while CHW aged 17-24 had no non compliance (0-50\%), while aged 25-45 had non compliance of $4 \%$ and the difference is statistically significant since the confidence interval 
Texila International Journal of Public Health

Volume 5, Issue 1, Mar 2017

doesn't overlap (Table 5). Intramuscular Injecting steps compliance by gender of CHW shows that majority complied, but male compliance is higher $(88.1 \%)$ than female $(80.9$ and the difference is significant since the confidence intervals don't overlap (Table 5). Intramuscular injecting steps compliance based on setting where injection conducted indicates that CHW's home performance looks a bit higher than the others ( home $89.6 \%$, health centre, $83.1 \%$, patient home $84 \%$ and other places $81 \%$, but the difference is not significant (Table 5).

\section{Discussion}

Community health workers complied to WHO guidelines for safe injection steps that can change health policy to add a new cadre for family planning services in the community setting. CHWs successfully followed infection prevention and intramuscular injection steps as established by WHO.

The objective of this study was to assess CHW compliance to WHO guideline of safe injection steps in community to inform policy makers on the evidence of capability of CHW to take over the task of distributing and administering the most popular and preferred by women injectable contraceptive, DMPA in Tanzania. Safety was addressed through ability of CHW to follow guideline of steps while administering injection. The community health workers in this study reported overall higher compliances to WHO guidelines of safe injection steps while injecting contraceptive. They have demonstrated compliance to infection prevention steps and intramuscular injecting steps as indicator of good training received from health care staffs of the ministry of health. They have demonstrated reliability for task shifting injectable contraceptive from overloaded health care workers to CHW.

\section{WHO infection prevention steps}

With respect to WHO compliances on infection prevention steps, CHW aged between 1825 are more likely to comply with guideline steps compared to CHW aged 25 years and above, while female CHWs are less likely to compliance to the guideline steps compared to male when receiving similar training. The CHWs are more likely to comply to WHO guideline steps to infection prevention when performing their activities at their own home compared to other places that the client may choose to get injection. This result findings may be contributed by the well know environment that $\mathrm{CHW}$ is used to provide injection procedure.

\section{WHO intramuscular injecting steps}

The majority of CHW complied with WHO guideline for safe intramuscular injecting steps. However young CHWs aged 17-24 are more likely to comply to all guideline if they are well taught and motivated, while at similar situation, CHW aged 25 and above are likely to non- compliance to the guidelines and instructions provided. Male CHWs are more likely to comply compare to their opposite gender. Based on setting where injection was given, CHW's home setting is the best place to help CHW to comply with guideline for intramuscular injecting steps, probably due to privacy and undisturbed environment where service is provided. Further study is needed to evaluate if CHW can provide more advanced long term family planning method of 'implant'.

\section{Conclusion}

The study indicated that CHWs can provide safe injection of Depo-provera. The findings help to inform the Ministry of Health that if CHW is well trained and prepared is capable of providing safe family planning services and can even increase access to contraceptives. The Ministry of Health can use this result for policy change and give opportunity to $\mathrm{CHW}$ to provide contraceptive services while reducing workload to health facility staffs. 


\section{Acknowledgements}

We would like to acknowledge the contribution professor James Phillips, and Colin Baynes from Columbia University, Kilombero district medical officer, project staffs and all participants for time and efforts to make this study successful. The study was funded by the United States International Development.

\section{References}

[1]. Alice Auma Olawo, Issak Bashir, Marsden Solomon, John Stanback, Baker Maggwa Ndugga, Isaac Malonza. 2013. A cup of tea with our CBD agent ...' ': community provision of injectable contraceptives in Kenya is safe and feasible. Global Health: Science and Practice 2013 | Volume 1 | Number 3.

[2]. Brunie A, Hoke TH, Razafindravony B. (2011). Community-based distribution of injectable contraceptives in an African setting: community trial in Madagascar. Sante.2011 Jan-Mar; 21(1):21-6. doi: 10.1684/san.2011.0232.

[3]. Coffey PS ${ }^{1}$, Sharma J, Gargi KC, Neupane D, Dawson P, Pradhan YV. (2012) Feasibility and acceptability of gentamicin in the Uniject prefilled injection system for community-based treatment of possible neonatalsepsis: the experience of female community health volunteers in Nepal. J Perinatol. 2012 Dec; 32(12):959-65. doi: 10.1038/jp.2012.20.

[4]. Gyawali S ${ }^{1}$, Rathore DS, Shankar PR, Kumar KV. (2013). Strategies and challenges for safe injection practice in developing countries. J Pharmacol Pharmacother. 2013 Jan; 4(1):8-12. doi: 10.4103/0976-500X.107634.

[5]. Kate Ramsey ${ }^{1,2^{*}}$, Ahmed Hingora ${ }^{2}$, Malick Kante ${ }^{1,2}$, Elizabeth Jackson ${ }^{1}$, Amon Exavery ${ }^{2}$, Senga Pemba $^{3}$, Fatuma Manzi ${ }^{2}$, Colin Baynes ${ }^{1,2}$, Stephane Helleringer, James F Phillips (2013). The Tanzania Connect Project: a cluster randomized trial of the child survival impact of adding paid community health workers to an existing facility-focused health system. BMC Health Serv Res. 2013;13 Suppl 2:S6. doi: 10.1186/1472-6963-13-S2-S6.

[6]. Nilsson J, Andrea B. Pembe, Miriam Urasa, and Elisabeth Darj (2013). Safe injections and waste management among healthcare workers at a regional hospital in northern Tanzania. Tanzania Journal of Health Research Doi: http://dx.doi.org/10.4314/thrb.v15i1.8 Volume 15, Number 1, January 2013.

[7]. Perez F, Ba H, Dastagire SG, Altmann M. (2009). The role of community health workers in improving child health programmes in Mali. BMC Int Health Hum Rights. (2009) Nov 10;9:28. doi: 10.1186/1472-698X-9-28.

[8]. Prüss-Üstün A, Rapiti E, Hutin Y. Estimation of the global burden of disease attributable to contaminated sharps injuries among health-care workers. American Journal of Industrial Medicine, 2005, 48(6):482-490. Retrieved from http://www.who.int/quantifying_ehimpacts/global/7sharps.pdf.

[9]. Tanzania (2004) National Infection Prevention and Control Guidelines for Health Care Services in Tanzania. Ministry of Health and Social welfare, The United Republic of Tanzania, Dar es Salaam.

[10]. World Health Organization, 2010. WHO Best Practices for Injections and Related Procedures

Toolkit Geneva: 2010 Mar. ISBN-13: 978-92-4-159925-2. Retrieved from http://www.ncbi.nlm.nih.gov/books/NBK138491/PubMed.

[11]. World Health Organization, 2015. WHO Guideline on the Use of Safety-Engineered Syringes for Intramuscular, Intradermal and Subcutaneous Injections in Health-Care Settings. Geneva: Retrieved from http://www.ncbi.nlm.nih.gov/books/NBK305368/. 
Texila International Journal of Public Health

Volume 5, Issue 1, Mar 2017

Table 1. Demographic characteristics of CHWs

\begin{tabular}{|l|l|l|l|}
\hline \multicolumn{4}{|c|}{ Demographic characteristics of CHWs } \\
\hline Variable & Response & Frequency & Percent \\
\hline $\begin{array}{l}\text { Age group in } \\
\text { years }\end{array}$ & $15-24$ & 8 & $23 \%$ \\
\hline & $25-45$ & 27 & $77 \%$ \\
\hline $\begin{array}{l}\text { Gender in } \\
\text { sex }\end{array}$ & Male & 21 & $60 \%$ \\
\hline & Female & 14 & $40 \%$ \\
\hline Total & & 35 & \\
\hline
\end{tabular}




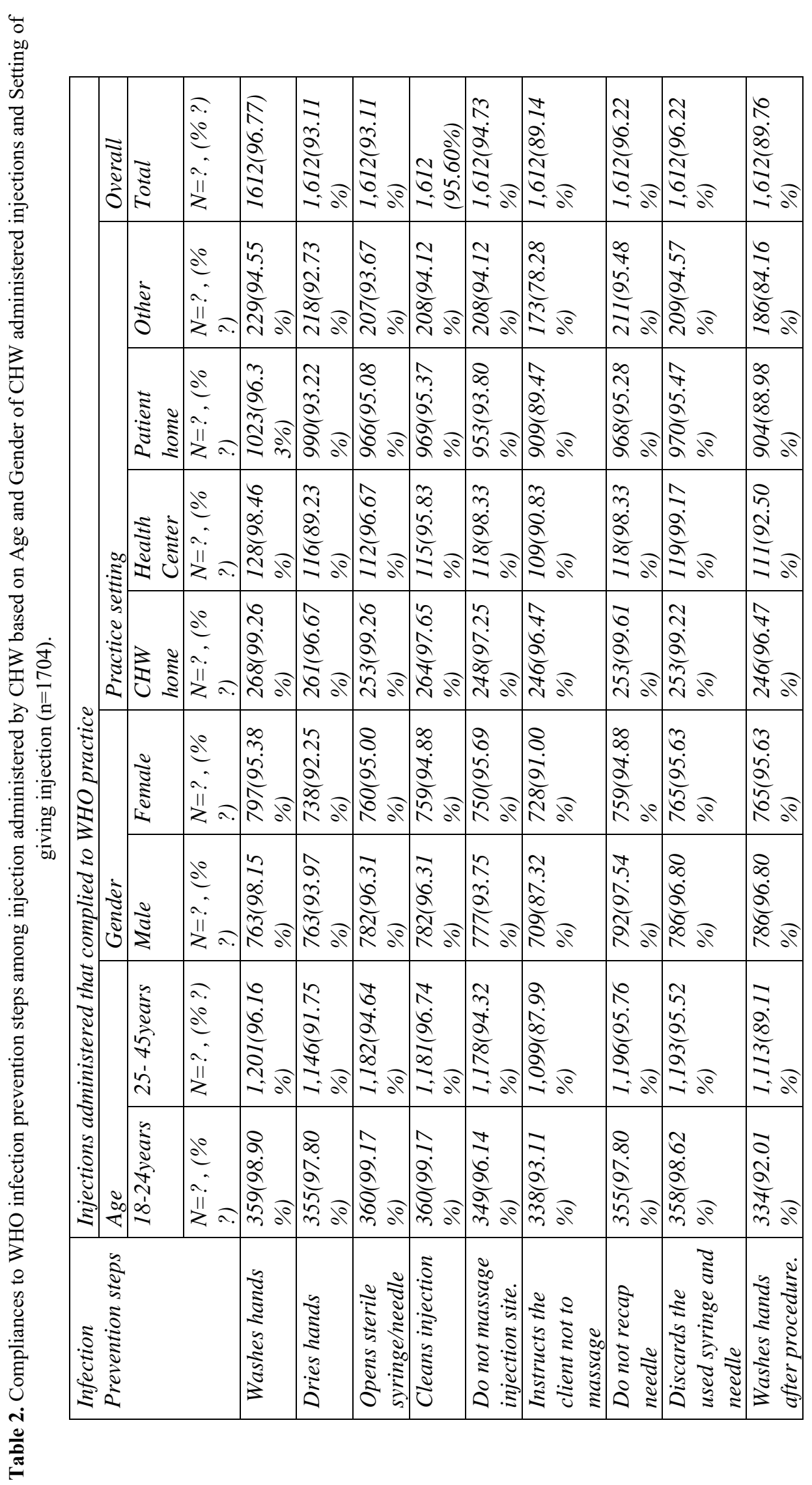




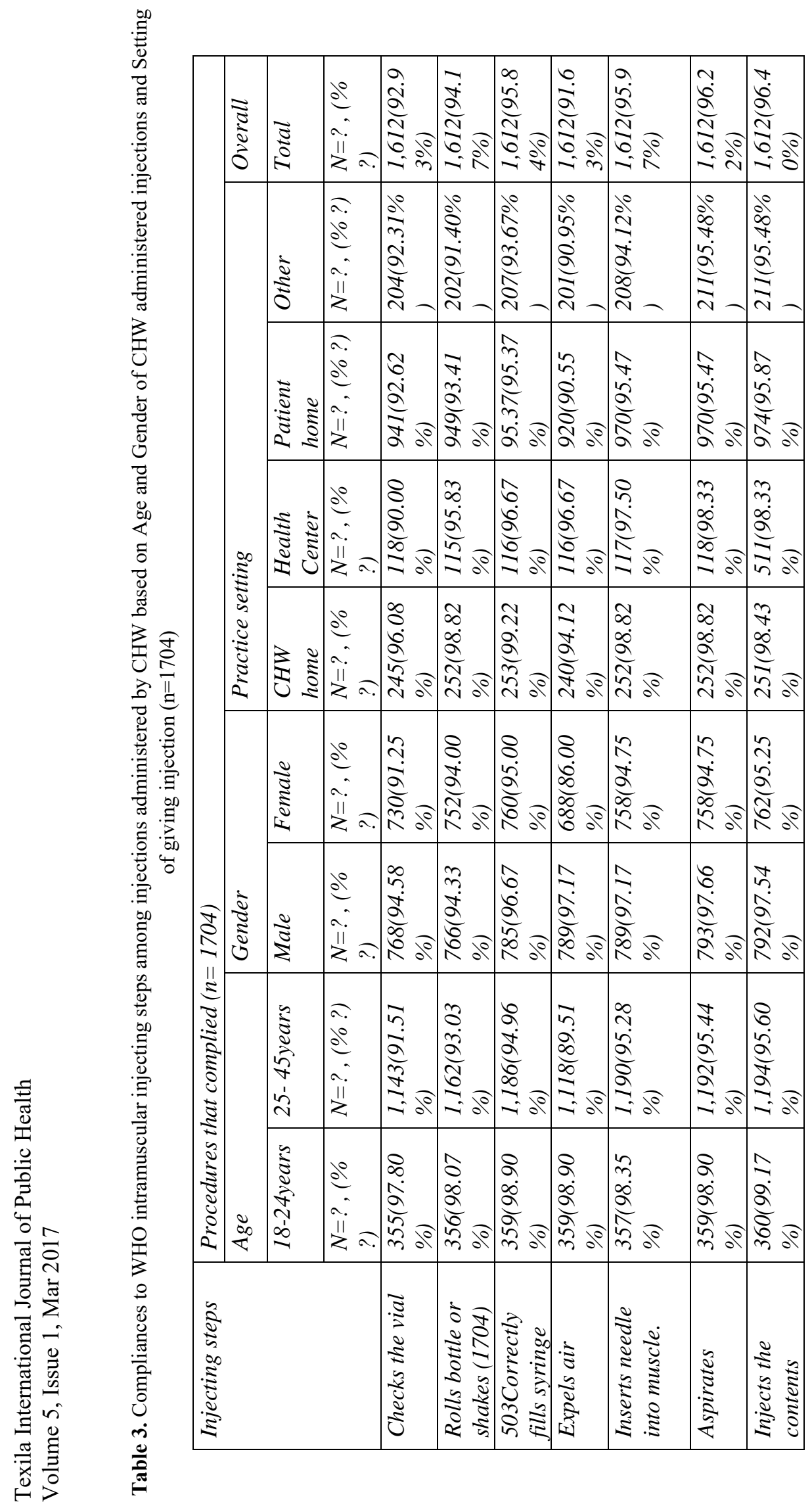


Texila International Journal of Public Health Volume 5, Issue 1, Mar 2017

Table 4. The Quantification of Infection prevention compliance performances

\begin{tabular}{|c|c|c|c|c|c|c|c|c|}
\hline \multirow{3}{*}{$\begin{array}{l}\text { Performance } \\
\text { level }\end{array}$} & \multicolumn{8}{|c|}{ Infection Prevention } \\
\hline & $\begin{array}{l}18- \\
24 y e a r s\end{array}$ & $\begin{array}{l}25- \\
45 y e a r s\end{array}$ & Male & Female & $\begin{array}{l}\text { CHW } \\
\text { home }\end{array}$ & $\begin{array}{l}\text { Health } \\
\text { Center }\end{array}$ & $\begin{array}{l}\text { Patient } \\
\text { home }\end{array}$ & Other \\
\hline & $\%(C I)$ & $\%(C I)$ & $\begin{array}{l}\% \\
(C I) \\
\end{array}$ & $\%(C I)$ & $\begin{array}{l}\% \\
(C I)\end{array}$ & $\%(C I)$ & $\%(C I)$ & $\%(C I)$ \\
\hline $\begin{array}{l}\text { Very Well } \\
(100 \%)\end{array}$ & $\begin{array}{l}79.3 \\
(74.9- \\
83.2)\end{array}$ & $\begin{array}{l}77.2 \\
(74.8- \\
79.4)\end{array}$ & $\begin{array}{l}74.9 \\
(71.8 \\
- \\
78.8)\end{array}$ & $\begin{array}{l}80.5 \\
(77.6- \\
83.1)\end{array}$ & $\begin{array}{l}90.7 \\
(86.6 \\
- \\
93.7) \\
\end{array}$ & $\begin{array}{l}80.0 \\
(72.2 \\
- \\
86.0)\end{array}$ & $\begin{array}{l}77.7 \\
(75.1- \\
80.1)\end{array}$ & $\begin{array}{l}59.4(52.8 \\
-65.6)\end{array}$ \\
\hline $\begin{array}{l}\text { Well (75- } \\
99) \%\end{array}$ & $\begin{array}{l}20.1 \\
(16.3- \\
24.6)\end{array}$ & $\begin{array}{l}17.2 \\
(15.2- \\
19.4)\end{array}$ & $\begin{array}{l}21.1 \\
(18.5 \\
- \\
24.1)\end{array}$ & $\begin{array}{l}14.5 \\
(12.2- \\
17.1)\end{array}$ & $\begin{array}{l}8.1 \\
(5.4- \\
12.1)\end{array}$ & $\begin{array}{l}13.8 \\
(8.9- \\
20.9)\end{array}$ & $\begin{array}{l}17.9 \\
(15.3- \\
19.9)\end{array}$ & $\begin{array}{l}34.4(28.4 \\
-40.9)\end{array}$ \\
\hline $\begin{array}{l}\text { Satisfactory } \\
(50-74) \%\end{array}$ & $\begin{array}{l}0.6(0.1 \\
-2.1)\end{array}$ & $\begin{array}{l}1.6(1.1 \\
-2.6)\end{array}$ & $\begin{array}{l}2.1 \\
(1.3- \\
3.3) \\
\end{array}$ & $\begin{array}{l}0.8 \\
(0.3- \\
1.7) \\
\end{array}$ & $\begin{array}{l}0.7 \\
(1.8- \\
2.9) \\
\end{array}$ & $\begin{array}{l}6.2 \\
(3.1- \\
11.9) \\
\end{array}$ & $\begin{array}{l}1.1(0.6 \\
-2.0)\end{array}$ & $\begin{array}{l}1.8(0.6- \\
4.7)\end{array}$ \\
\hline $\begin{array}{l}\text { Poor (0- } \\
50) \%\end{array}$ & & $\begin{array}{l}3.9(2.9 \\
-5.1)\end{array}$ & $\begin{array}{l}1.8 \\
(1.1 \\
- \\
3.0)\end{array}$ & $\begin{array}{l}4.2 \\
(3.1- \\
5.9)\end{array}$ & $\begin{array}{l}0.3(0 \\
-2.6)\end{array}$ & & $\begin{array}{l}3.7 \\
(2.7- \\
5.0)\end{array}$ & $\begin{array}{l}4.5(2.4- \\
8.1)\end{array}$ \\
\hline
\end{tabular}

Table 5. Quantification of Intramuscular Injection technical compliance performance

\begin{tabular}{|c|c|c|c|c|c|c|c|c|}
\hline \multirow{3}{*}{$\begin{array}{l}\text { Performan } \\
\text { ce level }\end{array}$} & \multicolumn{8}{|c|}{ Intramuscular Injection technical performance of steps } \\
\hline & $\begin{array}{l}18- \\
24 y e a r s\end{array}$ & $\begin{array}{l}25- \\
45 y e a \\
\text { rs }\end{array}$ & Male & Female & $\begin{array}{l}\text { CHW } \\
\text { home }\end{array}$ & $\begin{array}{l}\text { Health } \\
\text { Center }\end{array}$ & $\begin{array}{l}\text { Patient } \\
\text { home }\end{array}$ & Other \\
\hline & $\%(C I)$ & $\%(C I)$ & $\begin{array}{l}\% \\
(C I)\end{array}$ & $\%(C I)$ & $\%(C I)$ & $\%(C I)$ & $\%(C I)$ & $\%(C I)$ \\
\hline $\begin{array}{l}\text { Very Well } \\
(100 \%)\end{array}$ & $\begin{array}{l}91.7(88.4 \\
-94.2)\end{array}$ & $\begin{array}{l}82.4(8 \\
0.2- \\
84.4)\end{array}$ & $\begin{array}{l}88.1(8 \\
5.6- \\
90.1)\end{array}$ & $\begin{array}{l}80.9(78 \\
.0- \\
83.5)\end{array}$ & $\begin{array}{l}89.6(85 \\
.4- \\
92.8)\end{array}$ & $\begin{array}{l}83.1(75 \\
.6- \\
88.6)\end{array}$ & $\begin{array}{l}84.2(81 \\
.9- \\
86.3)\end{array}$ & $\begin{array}{l}81.7(76 \\
.1- \\
86.2)\end{array}$ \\
\hline $\begin{array}{l}\text { Well (75- } \\
99) \%\end{array}$ & $\begin{array}{l}6.6(4.5- \\
9.7)\end{array}$ & $\begin{array}{l}10.2(8 \\
.6- \\
12.0)\end{array}$ & $\begin{array}{l}7.6 \\
(6.0- \\
9.7))\end{array}$ & $\begin{array}{l}11.1 \\
(9.1- \\
13.5)\end{array}$ & $\begin{array}{l}8.9(6.0 \\
-12.9)\end{array}$ & $\begin{array}{l}12.3(7 . \\
7-19.2)\end{array}$ & $\begin{array}{l}8.9(7.4 \\
-10.8)\end{array}$ & $\begin{array}{l}9.8(6.5 \\
-14.5)\end{array}$ \\
\hline $\begin{array}{l}\text { Satisfactor } \\
\text { y (50- } \\
74) \%\end{array}$ & $\begin{array}{l}1.7(0.1- \\
3.6)\end{array}$ & $\begin{array}{l}3.4(2 . \\
5-4.6)\end{array}$ & $\begin{array}{l}2.5 \\
(1.6- \\
3.8)\end{array}$ & $\begin{array}{l}3.6(2.5 \\
-5.2)\end{array}$ & $\begin{array}{l}0.7(0.2 \\
-2.9)\end{array}$ & $\begin{array}{l}3.1(1.2 \\
-7.9)\end{array}$ & $\begin{array}{l}3.2(2.2 \\
-4.6)\end{array}$ & $\begin{array}{l}4.5(2.4 \\
-8.1)\end{array}$ \\
\hline $\begin{array}{l}\text { Poor (0- } \\
50) \%\end{array}$ & & $\begin{array}{l}4.0(3 . \\
0-5.2)\end{array}$ & $\begin{array}{l}1.8 \\
(1.1- \\
3.0) \\
\end{array}$ & $\begin{array}{l}4.4(3.2 \\
-6.0)\end{array}$ & $\begin{array}{l}0.7(0.2 \\
-2.9)\end{array}$ & $\begin{array}{l}1.5(3.8 \\
-6.0)\end{array}$ & $\begin{array}{l}3.6(2.6 \\
-4.9)\end{array}$ & $\begin{array}{l}4.0(2.1 \\
-7.6)\end{array}$ \\
\hline
\end{tabular}

